\title{
A stochastic estimate of the economic impact of oral calcium supplementation in postparturient dairy cows
}

\author{
J. A. A. McArt*1 and G. R. Oetzelt \\ ${ }^{*}$ Department of Population Medicine and Diagnostic Sciences, College of Veterinary Medicine, Cornell University, Ithaca, NY 14853 \\ †Department of Medical Sciences, School of Veterinary Medicine, University of Wisconsin, Madison 53706
}

\begin{abstract}
The objective was to develop stochastic models to estimate the economic impact in the first $30 \mathrm{~d}$ in milk of oral calcium supplementation to multiparous postparturient dairy cows using 4 different strategies: (1) supplementation of cows with a high previous lactation mature-equivalent milk yield, (2) supplementation of lame cows, (3) supplementation of both cows that have a high previous lactation mature-equivalent milk yield and cows that are lame, and (4) supplementation of all cows. Data from current literature were used to model input variables associated with the costs and risks related to milk production, postparturient disease, and culling. The mean net herd impact per 1,000 calvings for each of the 4 supplementation strategies was $\$ 4,425, \$ 5,812, \$ 8,313$, and $\$ 3,065$, respectively. Postpartum supplementation of multiparous lame cows had the highest return on investment at 6.5 to 1 , followed by supplementation of multiparous high milk yield and lame cows, multiparous high milk yield cows only, and supplementation of all multiparous postpartum cows with returns of 1.8 to $1,1.1$ to 1 , and 0.3 to 1 , respectively. A herd's average milk yield at first test had the highest influence on the net impact of oral calcium supplementation to all multiparous cows and accounted for $30 \%$ of the variation, followed by the decrease in risk of health events in lame cows given oral calcium at $22 \%$, a herd's prevalence of lameness at calving at $13 \%$, and the price of milk at $10 \%$. Each of the remaining stochastic variables contributed to less than $5 \%$ of the variation in net herd financial impact of oral calcium administration. Whereas supplementation of all postpartum multiparous cows returned a positive net herd impact approximately $80 \%$ of the time, if a herd was willing to devote time to mature-equivalent milk yield calculations and locomotion scoring, supplementation
\end{abstract}

Received February 18, 2015.

Accepted May 29, 2015.

${ }^{1}$ Corresponding author: jmcart@cornell.edu of this subpopulation of postpartum cows with oral calcium was estimated to have a positive economic impact in all iterations. Depending on the supplementation strategy chosen and baseline milk yield and immediate postpartum lameness prevalence in a herd, a herd with 1,000 calvings per year can expect to see an average net impact ranging from approximately $\$ 3,000$ to $\$ 8,000$ after postpartum supplementation of oral calcium in multiparous animals.

Key words: dairy cow, hypocalcemia, oral calcium, economic impact

\section{INTRODUCTION}

Hypocalcemia, defined as a low blood calcium concentration around the time of calving with or without clinical signs, is a costly problem for dairy producers. Compromises associated with hypocalcemia include reduced DMI at the start of lactation, decreased milk yield, increased risk for parturient diseases such as retained placenta, metritis, displaced abomasum (DA), and mastitis, increased risk for premature removal from the herd, and decreased reproductive performance (Chapinal et al., 2011, 2012; Martinez et al., 2012).

Prevention of hypocalcemia in postparturient dairy cows includes prepartum management to reduce DCAD, provision of a calcium-deficient diet, or vitamin D supplementation (Goff and Horst, 1997; Goff, 2004; Lean et al., 2006). Unfortunately, no on-farm, cost-effective diagnostic methods are available for individual animal blood calcium concentration measurement. Thus, it is often unknown if intervention in the immediate postpartum period is actually prevention or treatment of hypocalcemia. Common postpartum interventions include subcutaneous or intravenous administration of calcium salts, oral drenching with calcium propionate, or oral administration of calcium pastes or boluses (Pehrson et al., 1998; Goff, 2008; Oetzel and Miller, 2012). Because the postparturient calcium concentration of many animals receiving treatment is not known, benefits from these treatments are often measured by a 
lack of progression to a more severe hypocalcemia and subsequent development of clinical symptoms of milk fever or improvement in cows already diagnosed with milk fever.

Recent research by Oetzel and Miller (2012) showed the effectiveness of an oral calcium bolus (Bovikalc, Boehringer Ingelheim Vetmedica Inc., St. Joseph, MO) in improving early lactation milk yield and decreasing the number of postcalving health events in targeted subpopulations of multiparous cows, specifically cows with a high previous lactation mature-equivalent milk yield or that were lame at calving. However, the economic impact of treatment using oral calcium supplementation or other methods of calcium administration has not been explored.

Many economic analyses use deterministic modeling, which involves the use of fixed costs to estimate an outcome. Stochastic Monte Carlo modeling approaches are able to account not only for inputs normally used as fixed costs, such a disease risks and production costs, but also their variability (for example, fluctuations in the price of milk, cost of a replacement cow, and feed prices). This approach allows an estimation of the mean return on investment as well as a range around the estimate, providing a worst-case and best-case scenario and predictions of how likely each of these returns will occur.

The objective of this study was to develop stochastic Monte Carlo models to estimate the economic impact in the first 30 DIM of oral calcium supplementation to multiparous postparturient dairy cows using 4 different strategies: (1) supplementation of cows with a high previous lactation mature-equivalent milk yield, (2) supplementation of lame cows, (3) supplementation of both cows that have a high previous lactation matureequivalent milk yield and cows that are lame, and (4) supplementation of all cows.

\section{MATERIALS AND METHODS}

\section{Model Inputs}

Model input variables used to estimate the economic impact of oral calcium supplementation to multiparous postparturient dairy cows are in Table 1. Data used to create input variables are based on the following information.

Herd, Milk, Labor, and Feeding Inputs. Average milk yield at first test was based on data from approximately 1.3 million cows in 20,897 herds that send Dairy Herd Information Association (2014) data to Dairy Records Management Systems (Raleigh, NC). Mailbox milk prices were collected for 3 yr from 2011 to 2014 from the USDA Agricultural Marketing Service (2014b) and ranged from $\$ 0.38$ to $\$ 0.57$ per $\mathrm{kg}$ of milk. National average dairy feed cost data were collected for the same period from the University of Wisconsin (Gould, 2014) and ranged from $\$ 0.27$ to $\$ 0.38$ per $\mathrm{kg}$ of DM feed. Farm labor cost was based on information from the USDA Agricultural Marketing Service (2014b) after incorporating a 30\% increase to account for employee benefits. The times to conduct prefresh locomotion scoring, manage milk production and lameness data, identify a high mature-equivalent milk yield cow or lame cow and administer a calcium bolus, and manage a health event were based on field trials previously conducted by the research group. The costs of a calcium bolus and calcium administration gun were based on cost through a veterinary distributor (MWI Veterinary Supply, Boise, ID) with an additional 15\% markup.

Herd Removal Inputs. The risk of herd removal was based on data from McArt et al. (2015). The cost of a replacement cow was based on data collected during a 1-yr period from 2013 to 2014 through the USDA Agricultural Statistics Service (2014a) using a minimum and maximum value of $\$ 1,200$ and $\$ 1,650$, respectively. The value of a cow sent to slaughter (545 kg cow) was based on data collected during a 3-yr period from 2011 to 2014 through the USDA Agricultural Statistics Service (2014a) and ranged from $\$ 780$ to $\$ 1,452$. The disposal cost for a dead cow varied between on-farm composting and removal by a renderer and ranged from $\$ 0$ to $\$ 100$. The ratio of sold to dead cows in the first 30 DIM was based on unpublished data from McArt et al. (2012) and McConnel et al. (2008) and estimated at $60 \%$ sold and $40 \%$ death.

Disease Event Inputs. The risk of metritis, hyperketonemia, DA, mastitis, and pneumonia was based on unpublished data from Chapinal et al. (2011), McArt et al. (2013), Shaver (1997), Wilson et al. (2004) and Olde Riekerink et al. (2008), and the National Animal Health and Monitoring System (2007), respectively. The cost per case of metritis, hyperketonemia, and DA was based on McArt et al. (2015). The cost per case of mastitis was based on Rollin and Overton (2014). The cost per case of pneumonia was based on estimated discarded milk and treatment costs only because, to the authors' knowledge, no published estimates are available of a cost per case of pneumonia in adult animals. The increased risk of health events given lameness were based on Oetzel and Miller (2012), with a minimum increased risk of a health event for a lame cow of 1.31 and a maximum risk of 2.19 .

Health and Production Response Inputs. Variables associated with oral calcium supplementation health and production responses were based on data from Oetzel and Miller (2012). The mean effects were 
Table 1. Model inputs to estimate the economic return of oral calcium supplementation to multiparous postparturient dairy cows

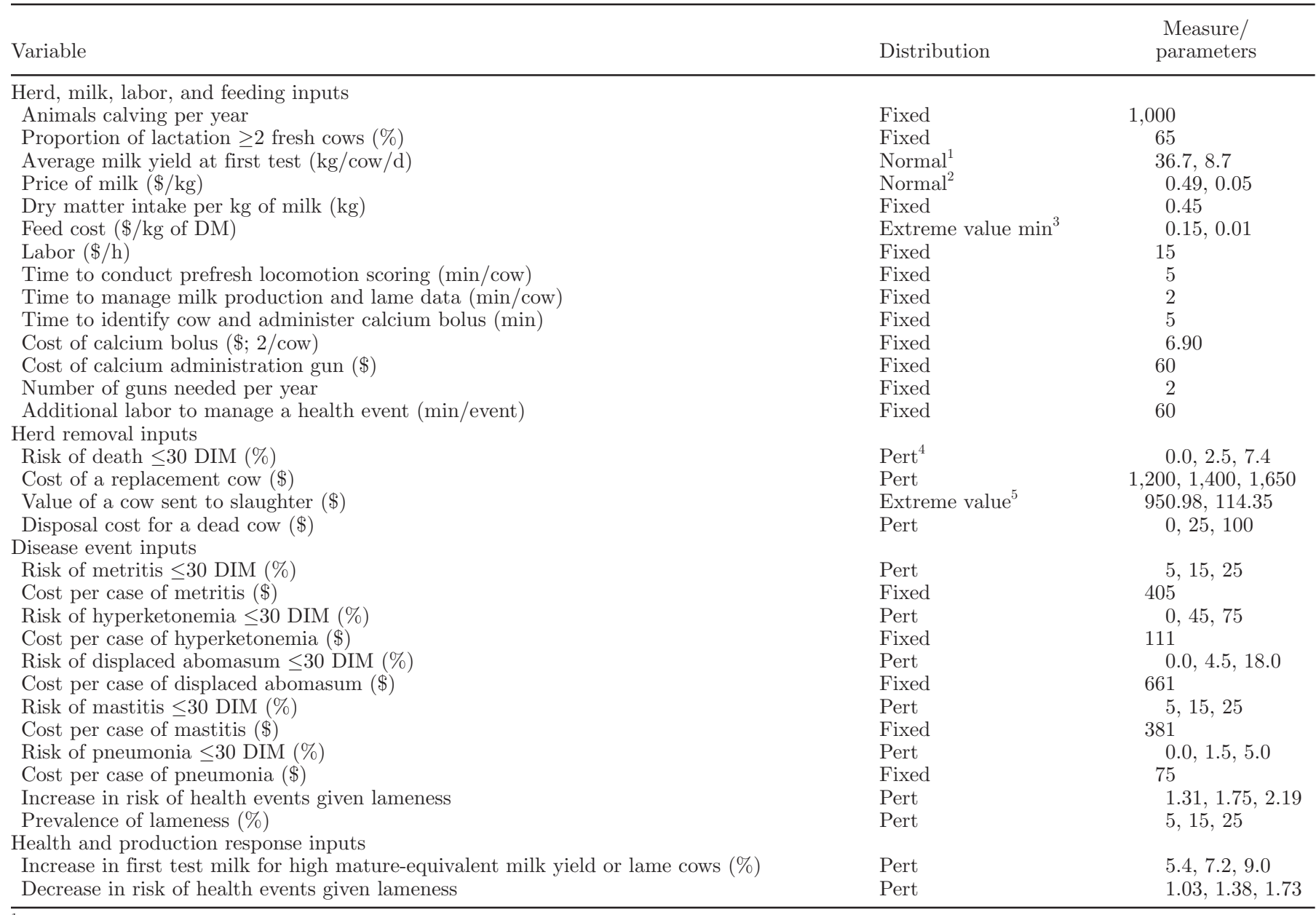

${ }^{1}$ Normal distribution includes mean and standard deviation parameters.

${ }^{2}$ Normal distribution truncated at a minimum value of $\$ 0.44$ and a maximum value of $\$ 0.57$.

${ }^{3}$ Extreme value min distribution includes $\alpha$ and $\beta$ parameters; this distribution was truncated at a minimum value of $\$ 0.06$ and a maximum value of $\$ 0.18$.

${ }^{4}$ Pert distribution includes minimum, most likely, and maximum parameters.

${ }^{5}$ Extreme value distribution includes $\alpha$ and $\beta$ parameters; this distribution was truncated at a minimum value of $\$ 700$ and a maximum value of $\$ 1,500$.

increased and decreased by $25 \%$ to obtain the minimum and maximum input values, respectively. This was done to account for potential herd variation in the response to the effect compared with herds used in the previously published study. Thus, the input values for the increase in first test milk for high mature-equivalent milk yield or lame cows supplemented with oral calcium ranged from $5.4 \%$ to $9.0 \%$, and the decrease in risk of health events for lame cows ranged from 1.03 to 1.73. A health event was considered the development of one or more of the following diseases in the first 30 DIM: hyperketonemia, metritis, DA, mastitis, or pneumonia. For strategies involving calcium supplementation of lame cows, the prevalence of lameness ranged from 5 to $25 \%$ and was based on Oetzel and Miller (2012), McNally et al. (2014), and Kougioumtzis et al. (2014). Supplementation of oral calcium was considered to occur at 2 time points, the first given within $2 \mathrm{~h}$ after calving and the second given the day after calving (approximately 8 to $32 \mathrm{~h}$ postpartum).

\section{Model Development}

A stochastic Monte Carlo partial budget model was developed using @Risk, version 6.3 (Palisade Corporation, Ithaca, NY). The model analyzed the following 4 simulated oral calcium supplementation strategies for multiparous postparturient dairy cows: (1) supplementation of cows with a high previous lactation matureequivalent milk yield, (2) supplementation of lame 
cows, (3) supplementation of both cows that have a high previous lactation mature-equivalent milk yield and cows that are lame, and (4) supplementation of all cows. These 4 simulations were chosen based on results of efficacy of oral calcium supplementation in the immediate postpartum period in 2 dairy herds being fed negative DCAD close-up prefresh rations (Oetzel and Miller, 2012). High mature-equivalent milk yield cows represent the top $45 \%$ of the herd based on previous lactation mature-equivalent milk yield, and lame cows represent animals with a prefresh locomotion score of 3 or 4 on a 4-point scale (Nordlund et al., 2004). All cows eligible for treatment were assumed to be administered oral calcium within $2 \mathrm{~h}$ of calving and on the day after calving.

Nonfixed variables had distribution functions fitted to the raw data by 1 of 2 methods. For input variables with a minimum, most likely, and maximum value (e.g., risk of hyperketonemia $\leq 30 \mathrm{DIM})$, a Pert distribution was chosen to emphasize the most likely value over the minimum and maximum values (i.e., the distribution allows for values around the most likely value to be chosen more often than the minimum or maximum estimates). For variables with repeated measurements over time (e.g., monthly mailbox milk price), distribution functions were fitted using @Risk's BestFit function that selects the best fitting distribution based on the selected data. A correlation matrix was added to account for possible correlations in variations between price of milk, feed cost, cost of a replacement heifer, and value of a cow sent to slaughter using the CORREL function in Excel (Microsoft, Redmond, WA). Correlations coefficients included in the models were cost of feed versus price of milk $(0.42, P<0.001)$, cost of feed versus value of a slaughter cow $(0.19, P=0.01)$, and price of milk versus value of a slaughter cow $(0.40$, $P=0.02)$.

Net herd impact was determined by the following formula:

$$
\begin{aligned}
& \text { increased revenues }+ \text { decreased costs } \\
& \text { - decreased revenues - increased costs. }
\end{aligned}
$$

Increased revenues were due to the value of increased milk sales; decreased costs were due to savings from fewer health events; decreased revenues were due to the value resulting from a decrease in herd removal; and increased costs were due to the cost of calcium boluses and guns and cost of on-farm labor for the supplementation program, and cost of increased feed intake to support extra milk production resulting from oral calcium supplementation.
Net impact per cow given oral calcium supplementation was determined by dividing the net herd impact by the total number of multiparous cows supplemented with calcium.

Return on investment (ROI) was calculated by the following formula:

$$
\begin{gathered}
\text { ROI }=(\text { net herd impact }) /(\text { cost per bolus treatment } \\
\times \text { number of dosed cows }) .
\end{gathered}
$$

A ROI $>0$ suggested a positive financial benefit of a treatment strategy. Model simulations were run using 10,000 iterations with replacement. Probability density and tornado graphs were produced using @Risk.

\section{RESULTS AND DISCUSSION}

Stochastic Monte Carlo modeling was conducted to estimate which simulated postpartum oral calcium supplementation strategy in multiparous cows provided the highest ROI. Based on previous research by Oetzel and Miller (2012), multiparous cows with a high previous lactation mature-equivalent and lame cows were more likely to benefit from postpartum oral calcium supplementation, which led to the development and testing of the following 4 strategies in multiparous animals: (1) supplementation of cows with a high previous lactation mature-equivalent milk yield, (2) supplementation of lame cows, (3) supplementation of both cows that have a high previous lactation mature-equivalent milk yield and cows that are lame, and (4) supplementation of all cows. Numerous inputs were modeled from data produced by Oetzel and Miller (2012) analyzing oral calcium administration to cows in herds fed a negative DCAD prefresh diet. As negative DCAD diets in the prepartum period have been found to increase blood calcium concentrations in the postpartum (Block, 1984; Oetzel et al., 1988), it is plausible that the modeled estimates may be conservative for herds that are not feeding prefresh anionic salts.

The net herd impact, net impact per dosed cow, and ROI for each of the 4 oral calcium supplementation strategies are given in Table 2. Postpartum supplementation of multiparous lame cows had the highest ROI at 6.5 to 1 , followed by supplementation of multiparous high mature-equivalent milk yield and lame cows, multiparous high mature-equivalent milk yield cows only, and supplementation of all multiparous postpartum cows with returns of 1.8 to $1,1.1$ to 1 , and 0.3 to 1 , respectively. Per 1,000 calvings, the mean net herd impact was highest for supplementation of multiparous high mature-equivalent milk yield and lame cows, followed 
Table 2. Results of Monte Carlo simulations estimating the net herd impact (based on a herd with 1,000 calvings per year, of which $65 \%$ are from multiparous cows), net impact per dosed cow, and return on investment of oral calcium supplementation to multiparous postparturient dairy cows in 4 different dosing strategies ${ }^{1}$

\begin{tabular}{|c|c|c|c|}
\hline Strategy & Mean & $95 \%$ range & SD \\
\hline Net herd impact $(\$)$ & 4,425 & $(87)$ to 9,835 & 2,508 \\
\hline Net impact per dosed cow $(\$)$ & 15 & 0 to 33 & 9 \\
\hline \multicolumn{4}{|l|}{ Lame cows } \\
\hline Net herd impact $(\$)$ & 5,812 & 1,614 to 11,403 & 2,523 \\
\hline Net impact per dosed cow $(\$)$ & 89 & 27 to 159 & 34 \\
\hline Net herd impact $(\$)$ & 8,313 & 1,875 to 15,775 & 3,540 \\
\hline Net impact per dosed cow $(\$)$ & 25 & 6 to 47 & 10 \\
\hline Return on investment & 1.8 & 0.5 to 3.4 & 0.8 \\
\hline \multicolumn{4}{|l|}{ All cows } \\
\hline Net herd impact $(\$)$ & 3,065 & $(3,377)$ to 10,634 & 3,587 \\
\hline Net impact per dosed cow $(\$)$ & 5 & (5) to 16 & 5 \\
\hline Return on investment & 0.3 & (0.4) to 1.2 & 0.4 \\
\hline
\end{tabular}

${ }^{1}$ Dosing strategies: (1) supplementation of cows with a high previous lactation mature-equivalent milk yield, (2) supplementation of lame cows, (3) supplementation of both cows that have a high previous lactation mature-equivalent milk yield and cows that are lame, and (4) supplementation of all cows. Parentheses denote a negative value.

by supplementation of multiparous lame cows only, all multiparous postpartum cows, and multiparous high mature-equivalent milk yield cows only.

Whereas supplementation of all multiparous lame cows provided the highest ROI, supplementation of multiparous high mature-equivalent milk yield and lame cows delivered the highest net herd impact. Although the net impact per dosed cow is less when supplementing the multiparous high mature-equivalent milk yield and lame cows, administration of oral calcium to a larger proportion of the herd that benefits from supplementation increases the net herd impact over that resulting from administration of oral calcium to only multiparous lame cows. Figure 1 depicts relative frequency graphs showing the net herd impact for the strategy with the highest ROI and the lowest ROI.

Although economically it may be more beneficial to strategically supplement either multiparous high mature-equivalent milk yield or lame cows, these 2 dosing strategies involve additional work on the part of farm employees. Records must be analyzed to determine which cows had high previous lactation mature-equivalent milk yield, and cows must be locomotion scored near or at calving. For herds that may be understaffed, have other time constraints, or have a larger return on their investment if this additional time is spent elsewhere, supplementation of all multiparous postpartum cows with oral calcium is still, on average, economically beneficial. Across 10,000 iterations of the model, 80.0\% of the time the net herd impact was greater than $\$ 0$; $59.3 \%$ of the simulations produced a net herd impact greater than $\$ 2,000$. Although not shown in Oetzel and Miller (2012), it is possible that cows other than mul- tiparous high mature-equivalent milk yield and lame cows benefit from additional calcium supplementation postpartum; thus, these results may be conservative estimates.

A tornado graph showing correlation coefficients between stochastic model input variables and net herd impact of oral calcium supplementation to all multiparous postpartum cows is in Figure 2. Only variables that contributed to $\geq 1 \%$ of the total variation in net herd impact were included in the graph. A herd's average milk yield at first test had the highest influence on the net herd impact of oral calcium supplementation to all multiparous cows; this variable alone accounted for $30 \%$ of the variation in the net herd impact under this strategy. Thus, herds that have a high average milk yield at first test may experience a larger ROI when supplementing all multiparous postpartum cows with oral calcium compared with herds with a low average milk yield at first test. Based on correlation coefficients, the decrease in risk of health events in lame cows given oral calcium accounted for approximately $22 \%$ of the variation, and a herd's risk of lameness at calving accounted for almost $13 \%$ of the variation in net herd impact of oral calcium supplementation to all multiparous postpartum cows. Thus, herds that experience a smaller decrease in risk of health events when supplementing lame cows with oral calcium will see a reduced net herd impact, and herds with a larger decrease will experience a greater net herd impact. Similarly, a herd with a higher risk of lameness will have a greater economic benefit from administration of oral calcium. The price of milk accounted for only $10 \%$ of the variation of net herd impact, and the increase in first test milk in high 
mature-equivalent milk yield or lame cows, DA risk in the first 30 DIM, hyperketonemia risk in the first 30 DIM, increase in risk of health events in lame cows, metritis risk in the first 30 DIM, and mastitis risk in the first 30 DIM each accounted for less than $5 \%$ of the variation in net herd impact. These results suggest that the benefits of postpartum oral calcium supplementation in multiparous cows are not greatly affected by various disease risks in a herd nor the price of milk.
Based on the results of the tornado graph, inputs that accounted for the greatest variation in net herd benefit (average milk at first test, the decrease in risk of health events in lame cows, and lameness risk at calving) were individually modified to demonstrate their effect on the economic outcome of oral calcium supplementation to all multiparous cows. Figures 3, 4, and 5 show relative frequency graphs with various fixed-variable alterations in the net impact per dosed cow. Alteration of the aver-
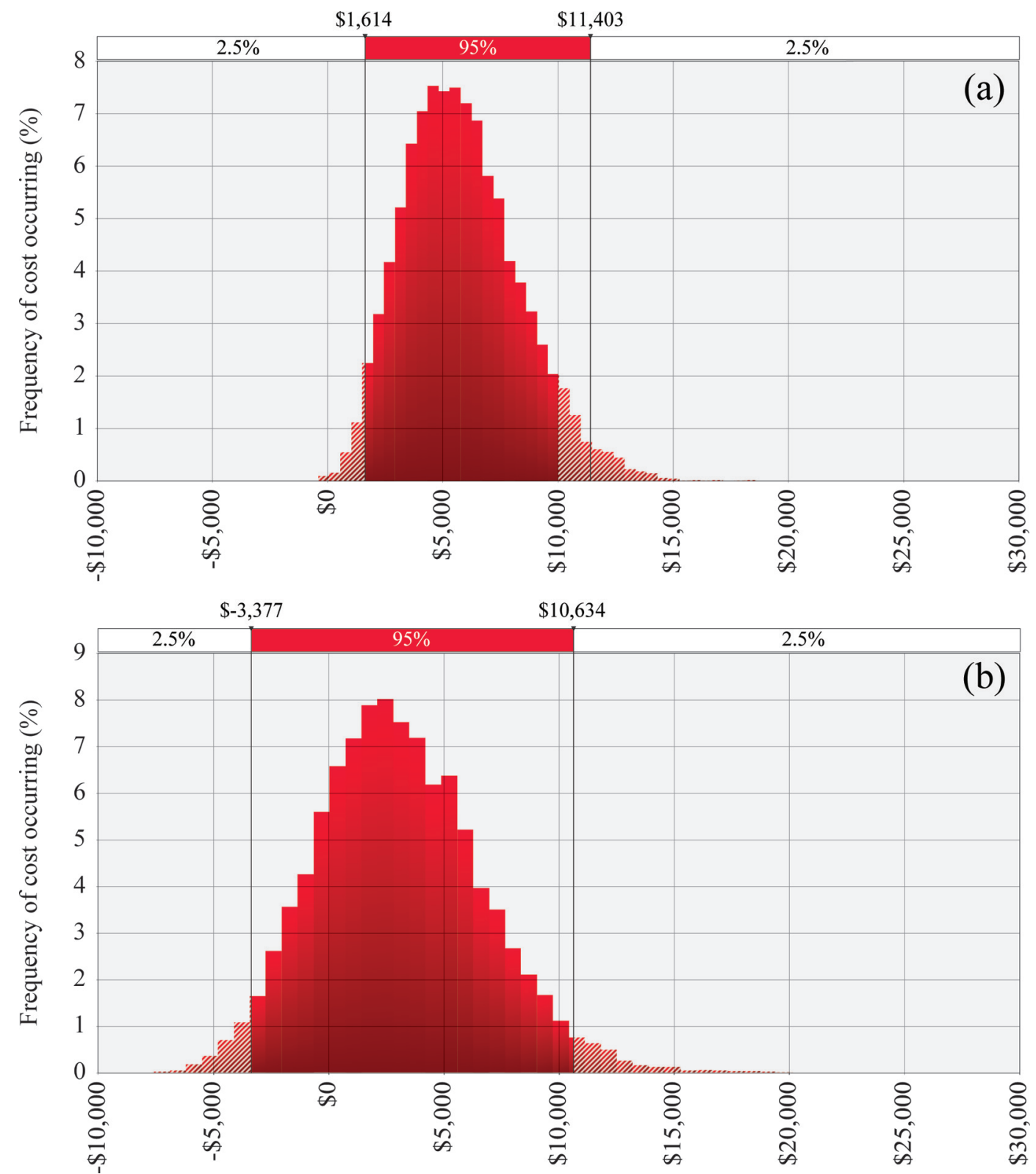

Figure 1. Relative frequency graphs showing 10,000 iterations of the net herd impact (based on a herd with 1,000 calvings per year) for the most cost-effective strategy for (a) oral calcium supplementation of postpartum multiparous lame cows (mean $=\$ 5,812$ ), and the least costeffective dosing strategy, and (b) oral supplementation of all postpartum multiparous cows (mean $=\$ 3,065)$. Color version available online. 


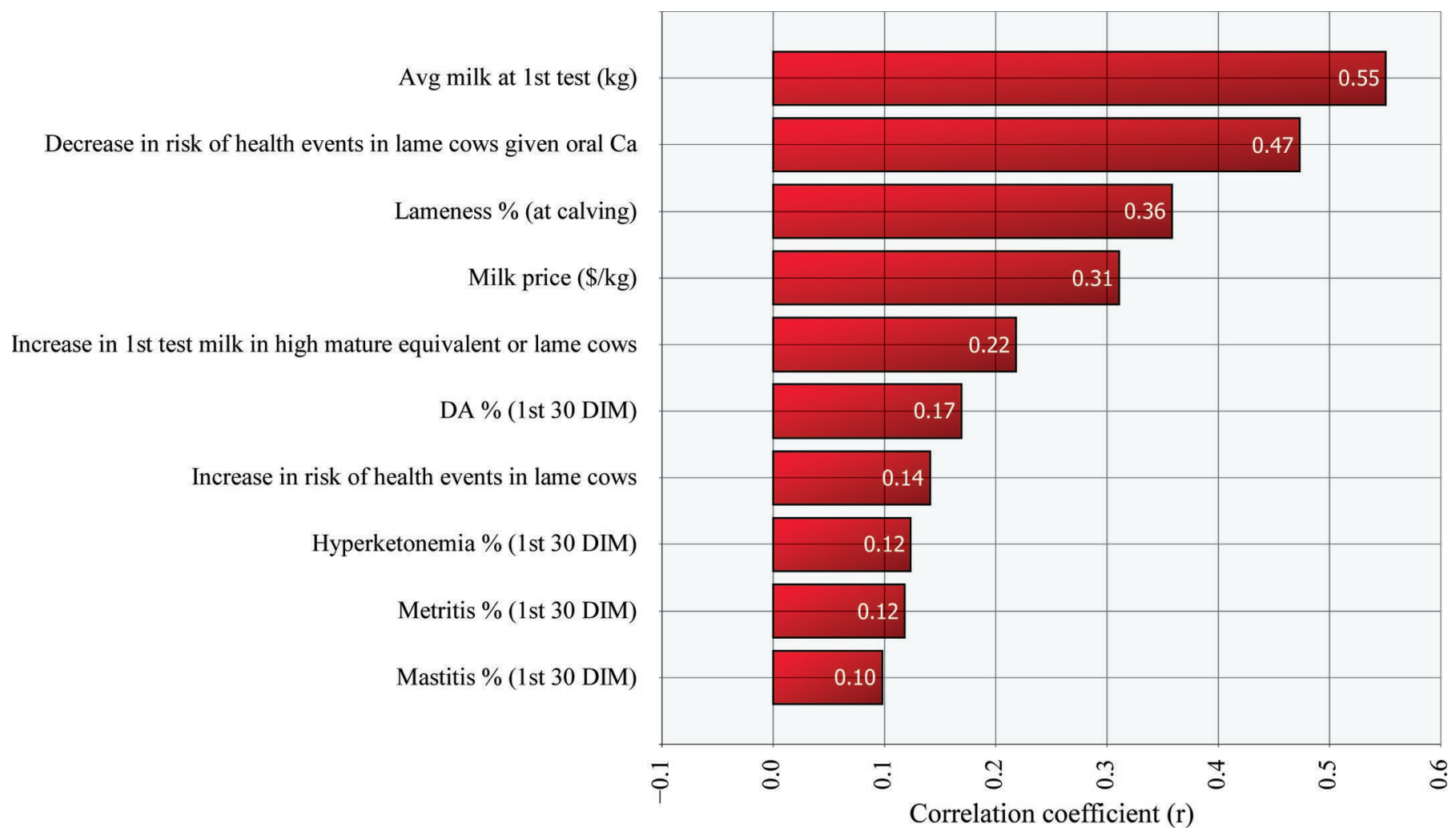

Figure 2. Tornado graph showing correlation coefficients between model input variables and net herd impact of oral calcium supplementation to all multiparous postpartum cows. Stochastic variables used in the model included the average milk yield at first test, milk price, cost of feed, death loss in the first 30 DIM, disposal cost of a dead cow, value of a replacement cow, value of a slaughter cow, metritis risk in the first 30 DIM, hyperketonemia risk in the first 30 DIM, displaced abomasum (DA) risk in the first 30 DIM, mastitis risk in the first 30 DIM, pneumonia risk in the first 30 DIM, risk of lameness at calving, increase in first test milk for high mature-equivalent milk yield cows or lame cows given oral calcium supplementation, increase in risk of health events in lame cows, and decrease in risk of health events for lame cows given oral calcium supplementation. Only variables that contributed to $\geq 1 \%$ of the variation in net herd impact were included in the graph. Color version available online.

age milk at first test from the minimum to maximum input values used in the model $(28.0 \mathrm{~kg}$ to $45.5 \mathrm{~kg}$ ) changed the net impact per dosed cow from $\$ 2$ to $\$ 8$, which well characterizes the larger financial benefit that herds with a high average milk yield at first test may see over herds with a low average milk yield at first test. Alteration of the decrease in risk of health events in lame cows given oral calcium supplementation from the minimum to maximum input values used in the model (1.03 to 1.73) changed the net impact per dosed cow from $-\$ 4$ to $\$ 10$. Although this difference per cow is large, it is difficult to assess an individual herd's risk response to oral calcium supplementation in lame cows, thus individual herd determination of this input is not practical from a management standpoint. Alteration of the lameness risk at calving from the minimum to maximum input values used in the model (5\% to 15\%) increased the net impact per dose cow from $-\$ 1$ to $\$ 10$. It follows that as a herd's lameness risk at calving increases, the benefits of oral calcium supplementation will increase, and thus the net impact per dosed cow will improve substantially.

Based on Monte Carlo simulations, supplementation of high mature-equivalent milk yield and lame multiparous cows in the immediate postpartum period with oral calcium provided the highest net herd impact. The largest ROI was seen when only multiparous lame cows were supplemented with oral calcium postpartum. Because much of the data used to develop the oral calcium-related variables in the Monte Carlo simulations was based on Oetzel and Miller (2012) and this study was conducted in only 2 herds, it is possible that limiting the health and production benefits from oral calcium supplementation to only multiparous high mature-equivalent milk yield cows and lame cows provides a conservative estimate of the true net financial impact. Whereas supplementation of all postpartum multiparous cows returned a positive net herd impact approximately $80 \%$ of the time, if a herd was willing to devote time to mature-equivalent milk yield calcula- 

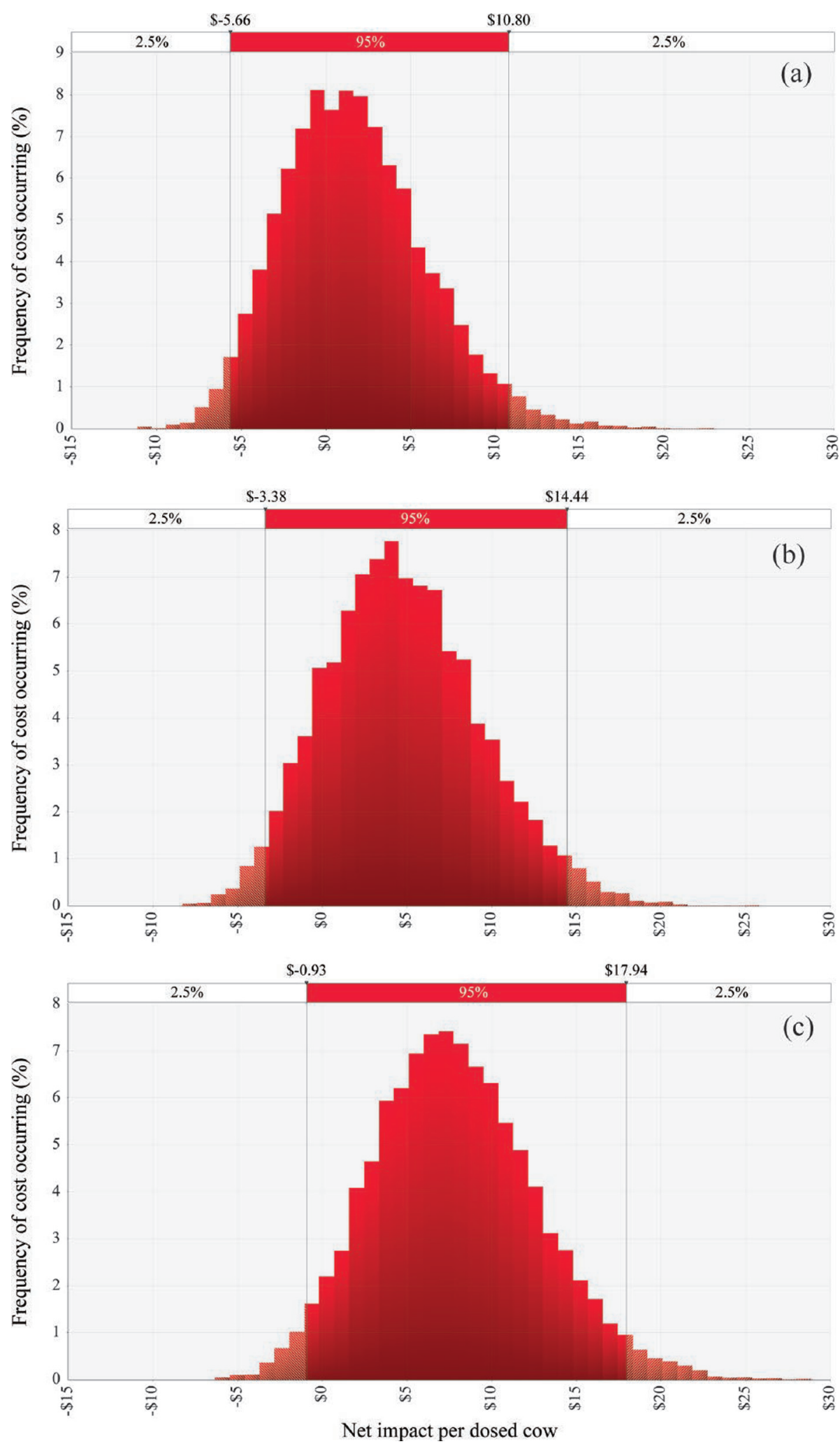

Figure 3. Relative frequency graphs showing 10,000 iterations of the net impact per dosed cow for the least cost-effective supplementation strategy, supplementation of all multiparous postpartum cows with oral calcium, with the "average milk yield at first test" variable entered in the model using 3 different fixed input values: (a) $28.0 \mathrm{~kg}$, (b) $36.7 \mathrm{~kg}$, and (c) $45.4 \mathrm{~kg}$, which represent the minimum, most likely, and maximum values previously entered into the stochastic model. The mean net impact per dosed cow at the 3 different inputs was estimated to be $\$ 2$, $\$ 5$, and $\$ 8$, respectively. Color version available online. 

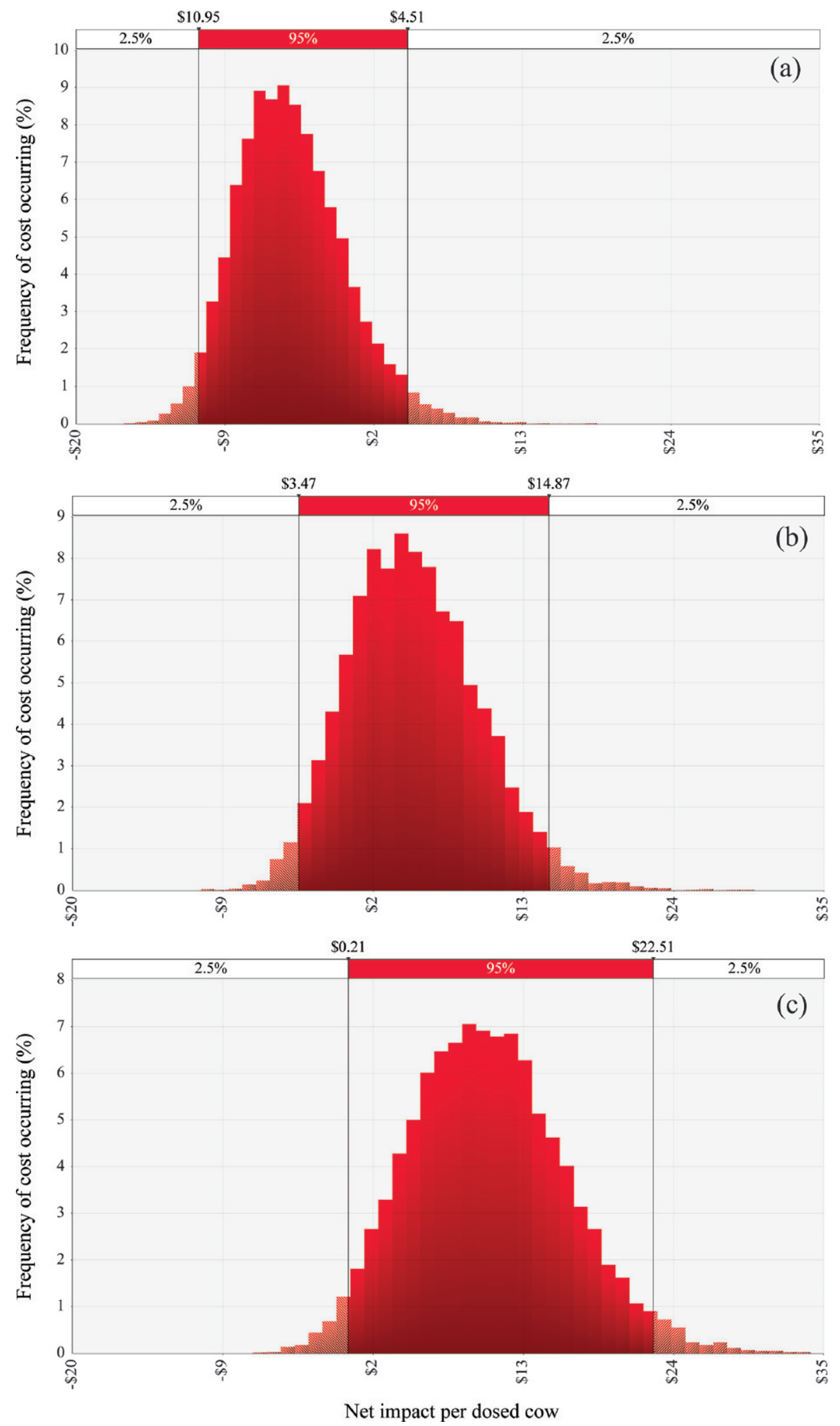

Figure 4. Relative frequency graphs showing 10,000 iterations of the net impact per dosed cow for the least cost-effective supplementation strategy, supplementation of all multiparous postpartum cows with oral calcium, with the "decrease in risk of health events in lame cows given oral calcium supplementation" variable entered into the model using 3 different fixed input values: (a) 1.03, (b) 1.38, and (c) 1.73, which represent the minimum, most likely, and maximum values previously entered into the stochastic model. The mean net impact per dosed cow at the 3 different inputs was estimated to be $-\$ 4, \$ 5$, and $\$ 10$, respectively. Color version available online. 

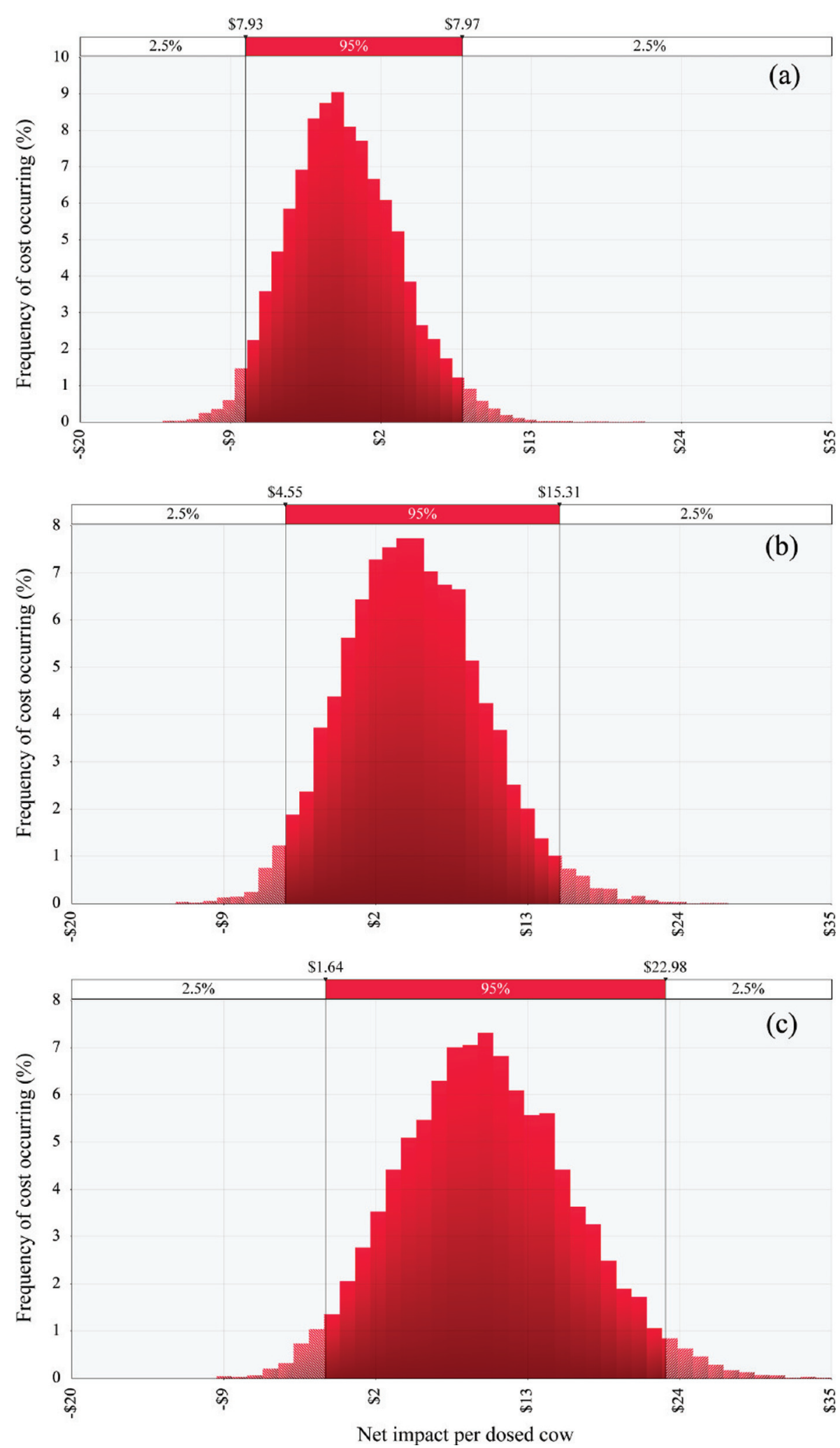

Figure 5. Relative frequency graphs showing 10,000 iterations of the net impact per dosed cow for the least cost-effective supplementation strategy, supplementation of all multiparous postpartum cows with oral calcium, with the "risk of lameness at calving" variable entered into the model using 3 different fixed input values: (a) $5 \%$, (b) 10\%, and (c) 15\%, which represent the minimum, most likely, and maximum values previously entered into the stochastic model. The mean net impact per dosed cow at the 3 different inputs was estimated to be $-\$ 1$, $\$ 5$, and $\$ 10$, respectively. Color version available online. 
tions and locomotion scoring, supplementation of this subpopulation of postpartum cows with oral calcium was estimated to have a positive economic impact in all iterations.

\section{CONCLUSIONS}

Depending on the supplementation strategy chosen and baseline milk yield and immediate postpartum lameness prevalence in a herd, a herd with 1,000 calvings per year can expect to see an average net impact ranging from approximately $\$ 3,000$ to $\$ 8,000$ after postpartum supplementation of oral calcium to multiparous animals.

\section{ACKNOWLEDGMENTS}

This study was funded in part by Boehringer Ingelheim Vetmedica Inc. (St. Joseph, MO).

\section{REFERENCES}

Block, E. 1984. Manipulating dietary anions and cations for prepartum dairy cows to reduce incidence of milk fever. J. Dairy Sci. 67:2939-2948.

Chapinal, N., M. Carson, T. F. Duffield, M. Capel, S. Godden, M. Overton, J. E. P. Santos, and S. J. LeBlanc. 2011. The association of serum metabolites with clinical disease during the transition period. J. Dairy Sci. 94:4897-4903.

Chapinal, N., M. E. Carson, S. J. LeBlanc, K. E. Leslie, S. Godden, M. Capel, J. E. P. Santos, M. W. Overton, and T. F. Duffield. 2012. The association of serum metabolites in the transition period with milk production and early-lactation reproductive performance. J. Dairy Sci. 95:1301-1309.

Dairy Herd Information Association. 2014. Dairy Records Management Systems. Raleigh, NC. Accessed Jul. 14, 2014. www.drms. org.

Goff, J. P. 2004. Macromineral disorders of the transition cow. Vet. Clin. North Am. Food Anim. Pract. 20:471-494.

Goff, J. P. 2008. The monitoring, prevention, and treatment of milk fever and subclinical hypocalcemia in dairy cows. Vet. J. 176:50-57.

Goff, J. P., and R. L. Horst. 1997. Effects of the addition of potassium or sodium, but not calcium, to prepartum rations on milk fever in dairy cows. J. Dairy Sci. 80:176-186.

Gould, B. 2014. Understanding dairy markets. Dairy feed cost. Accessed Oct. 14, 2014. http://future.aae.wisc.edu.

Kougioumtzis, A., G. E. Valergakis, G. Oikonomou, G. Arsenos, and G. Banos. 2014. Profile and genetic parameters of dairy cattle locomotion score and lameness across lactation. Animal 8:20-27.

Lean, I. J., P. J. DeGaris, D. M. McNeil, and E. Block. 2006. Hypocalcemia in dairy cows: Meta-analysis and dietary cation anion difference theory revisited. J. Dairy Sci. 89:669-684.
Martinez, N., C. A. Risco, F. S. Lima, R. S. Bisinotto, L. F. Grego E. S. Riberio, F. Maunsell, K. Galvão, and J. E. P. Santos. 2012. Evaluation of peripartal calcium status, energetic profile, and neutrophil function in dairy cows at low or high risk of developing uterine disease. J. Dairy Sci. 95:7158-7172.

McArt, J. A. A., D. V. Nydam, and G. R. Oetzel. 2012. Epidemiology of subclinical ketosis in early lactation dairy cattle. J. Dairy Sci. 95:5056-5066.

McArt, J. A. A., D. V. Nydam, G. R. Oetzel, T. R. Overton, and P. A. Ospina. 2013. Elevated nonesterified fatty acids and betahydroxybutyrate and their association with transition dairy cow performance. Vet. J. 198:560-570.

McArt, J. A. A., D. V. Nydam, and M. W. Overton. 2015. Hyperketonemia in early lactation dairy cattle: A deterministic estimate of component and total cost per case. J. Dairy Sci. 98:2043-2054.

McConnel, C. S., J. E. Lombard, B. A. Wagner, and F. B. Garry. 2008 Evaluation of factors associated with increased dairy cow mortality on United States dairy operations. J. Dairy Sci. 91:1423-1432.

McNally, J. C., M. A. Crowe, J. F. Roche, and M. E. Beltman. 2014. Effects of physiological and/or disease status on the response of postpartum dairy cows to synchronization of estrus using an intravaginal progesterone device. Theriogenology 82:1263-1272.

National Animal Health Monitoring System. 2007. Part III: Reference of dairy cattle health and management practices in the United States. United States Department of Agriculture, Animal and Plant Health Inspection Service.

Nordlund, K. V., N. B. Cook, and G. R. Oetzel. 2004. Investigation strategies for laminitis problem herds. J. Dairy Sci. 87:E27-E35.

Oetzel, G. R., and B. E. Miller. 2012. Effect of oral calcium bolus supplementation on early-lactation health and milk yield in commercial dairy herds. J. Dairy Sci. 95:7051-7065.

Oetzel, G. R., J. D. Olson, C. R. Curtis, and M. J. Fettman. 1988. Ammonium chloride and ammonium sulfate for prevention of parturient paresis in dairy cows. J. Dairy Sci. 71:3302-3309.

Olde Riekerink, R. G. M., H. W. Barkema, D. F. Kelton, and D. T. Scholl. 2008. Incidence rate of clinical mastitis on Canadian dairy farms. J. Dairy Sci. 91:1366-1377.

Pehrson, B., C. Svensson, and M. Jonsson. 1998. A comparative study of the effectiveness of calcium propionate and calcium chloride for the prevention of parturient paresis in dairy cows. J. Dairy Sci. 81:2011-2016.

Rollin, E., and M. W. Overton. 2014. The cost of clinical mastitis in the first $30 \mathrm{~d}$ of lactation: An economic assessment tool. J. Dairy Sci. 97(E-Suppl. 1):290. (Abstr.)

Shaver, R. D. 1997. Nutritional risk factors in the etiology of left displaced abomasum in dairy cows: A review. J. Dairy Sci. 80:24492453

USDA Agricultural Statistics Service. 2014a. Data and statistics. Accessed Oct. 14, 2014. http://www.nass.usda.gov.

USDA Agricultural Marketing Service. 2014b. Marketing orders. Mailbox prices. Accessed Oct. 14, 2014. http://www.ams.usda.gov.

Wilson, D. J., R. N. González, J. Hertl, H. F. Schulte, G. J. Bennett, Y. H. Schukken, and Y. T. Gröhn. 2004. Effect of clinical mastitis on the lactation curve: A mixed model estimation using daily milk weights. J. Dairy Sci. 87:2073-2084. 